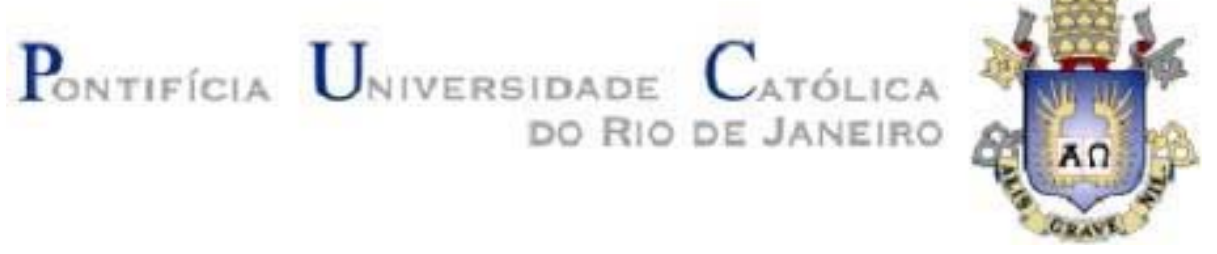

Filipe Ribeiro Dantas

A Atitude dos Clientes do Instituto de Beleza Natural

Dissertação de Mestrado

Dissertação apresentada ao Programa de Pósgraduação em Administração de Empresas da PUCRio como requisito parcial para obtenção do Titulo de Mestre em Administração de Empresas.

Orientador: Prof. Paulo Cesar de Mendonça Motta 


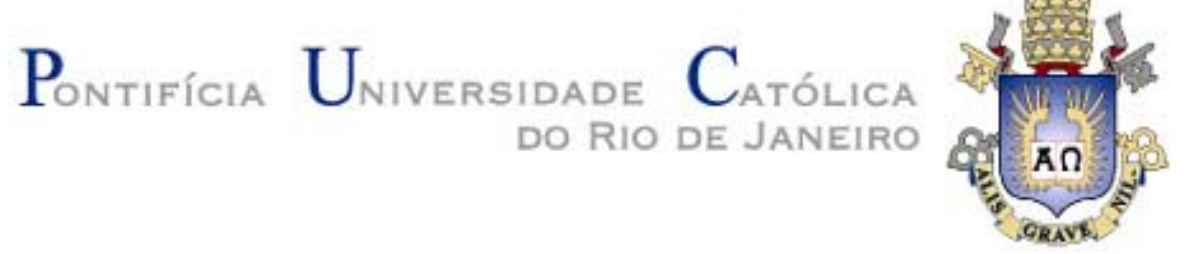

Filipe Ribeiro Dantas

\section{A atitude dos clientes do Instituto de Beleza Natural}

Dissertação apresentada como requisito parcial para obtenção do grau de Mestre pelo Programa de Pósgraduação em Administração de Empresas da PUC-Rio. Aprovada pela Comissão Examinadora abaixo assinada.

Prof. Paulo Cesar de Mendonça Motta

Orientador

Departamento de Administração - PUC-Rio

Prof ${ }^{a}$. Veranise Jacubowski Correia Dubeux

Departamento de Administração - PUC-Rio

Prof. Eduardo Halpern

ESPM - RJ

Prof ${ }^{a}$. Mônica Herz

Vice-Decana de Pós-Graduação do CCS

Rio de Janeiro, 10 de setembro de 2010 
Todos os direitos reservados. É proibida a reprodução total ou parcial do trabalho sem autorização da universidade, do autor e do orientador.

\section{Filipe Ribeiro Dantas}

Graduou-se em Administração de Empresas com habilitação em Marketing na Escola Superior de Propaganda e Marketing, ESPM-Rio, em 2006. Como profissional exerceu cargo executivo na Rádio Catedral FM do Rio de Janeiro. Atualmente é sócio-diretor da Sistêmica Comunicação, empresa que presta assessoria para Captação de Recursos e Marketing Direto para diversas associações como Arautos do Evangelho, Pastoral do Menor do Rio de Janeiro, Seminário São José, Pequena Cruzada de Santa Therezinha, Associação Católica Nossa Senhora de Fátima e Associação Religiosa Nossa Senhora das Graças.

Ficha Catalográfica

Dantas, Filipe Ribeiro

A atitude dos clientes do Instituto de Beleza Natural / Filipe Ribeiro Dantas ; orientador: Paulo Cesar de Mendonça Motta. - 2010.

102 f. : il. (color.) ; $30 \mathrm{~cm}$

Dissertação (mestrado)-Pontifícia Universidade Católica do Rio de Janeiro, Departamento de Administração, 2010.

Inclui bibliografia

1. Administração - Teses. 2. Baixa renda. 3. Cabelos crespos. 4. Autoestima. 5. Atitude. 6. Raça negra. I. Motta, Paulo Cesar de Mendonça. II. Pontifícia Universidade Católica do Rio de Janeiro. Departamento de Administração. III. Título. 
Para Maria e Gabriel, os amores de minha vida. 


\section{Agradecimentos}

Antes de tudo devo agradecer à minha família pelo apoio e incentivo que me deram para realizar o Mestrado e a presente dissertação.

Agradeço também aos professores do IAG da PUC-Rio pelos ensinamentos ministrados durante as aulas do curso.

Não poderia esquecer dos meus colegas de curso, em especial pelos que formam o conhecido "Dream Team" - André Basile, André Neiva, Nivaldo Barro e Juarez Sigwault - que formaram comigo um vitorioso grupo de estudos e trabalhos ao longo dos dois anos em que frequentamos juntos as aulas na PUC.

Quero agradecer também de modo especial à amiga e ex-colega de graduação Leila Veles, sócia do Beleza Natural, pela receptividade demonstrada e ajuda fornecida, que possibilitou a presente pesquisa. Lembro também de todas as funcionárias e clientes do Instituto que com seus depoimentos deram o embasamento para o estudo.

Por fim a minha gratidão se volta de forma especial para o Professor Paulo César Motta, meu orientador, pela paciência e clarividência que teve no trabalho de dirigir a presente dissertação. 


\section{Resumo}

Dantas, Filipe Ribeiro; Motta, Paulo Cesar de Mendonça. A Atitude dos

Clientes do Instituto de Beleza Natural. Rio de Janeiro, 2010. 102p. Dissertação de Mestrado - Departamento de Administração, Pontifícia Universidade Católica do Rio de Janeiro.

Este trabalho investiga a formação de atitudes dos clientes do Instituto Beleza Natural, um salão especializado em cabelos crespos. Estuda, particularmente, o desenvolvimento de atitudes positivas em relação aos serviços oferecidos pelo Instituto de Beleza Natural, procurando explicar o sucesso da empresa. Foram realizadas várias entrevistas com clientes do Instituto para identificar temas associados tanto às restrições como aos estímulos associados à utilização dos serviços oferecidos. Os resultados indicam um conjunto significativo de temas relacionados à atitude como: desejo de modificar o cabelo, cabelo não cresce, preconceito na escola, cabelo arrumado ajuda a conseguir um emprego, melhora a autoestima, atrai o olhar dos rapazes etc. Todas as temáticas foram analisadas e associadas às problemáticas de acordo com método sugerido por Guerra (2006). As principais problemáticas, como por exemplo, os sacrifícios financeiros para fazer o tratamento no Beleza Natural, as excluídas do Beleza, as que desprezam o Beleza Natural, são analisadas na perspectiva das implicações gerenciais. Algumas dessas implicações podem ajudar empresas que focam em problemas semelhantes. Podem ajudar também as que buscam atender necessidades de consumo nas camadas de baixa renda.

\section{Palavras-chave}

Baixa renda; cabelos crespos; autoestima; atitude; raça negra. 


\section{Abstract}

Dantas, Filipe Ribeiro; Motta, Paulo Cesar de Mendonça (Advisor). Customer Attitudes Towards the Beleza Natural Institute. Rio de Janeiro, 2010. 102p. MSc. Dissertation - Departamento de Administração, Pontifícia Universidade Católica do Rio de Janeiro.

This work aims to understand how the attitudes of the clients of Instituto de Beleza Natural (a beauty salon that specializes in afro textured hair) have been fostered. It focuses particularly on the development of positive attitudes regarding the services offered by the Instituto Beleza Natural in order to explain the Instituto's commercial success. It was decided that the best method to adopt for this research was to undertake several in depth interviews with clients of the Instituto. This approach enabled the researcher to identify themes related not only to the stimuli for using the services offered, but also to pin point the restrictions to them. The results show a significant amount of themes related to attitude, such as the wish for a different sort of hair, hair that won't grow longer, prejudice at school, neat hair helps to find a job, it helps self-esteem, it attracts the boys' eyes, and so on. All the themes were analyzed and associated to the problems according to the method suggested by Guerra (2006). The main problems (such as financial difficulties to undergo the treatment at the Beleza Natural, the people who were excluded from it and the ones who scorn it ) are analyzed in the perspective of managerial implications. Some of these implications may be of value for other businesses with similar problems. They may also help those that target catering for the needs of low income clients.

\section{Keywords}

Low income; black hair; self-esteem; attitude; black race. 


\section{Sumário}

1. Introdução 13

2. Referencial Teórico 15

2.1. A Riqueza na Base da Pirâmide 15

2.2. Pobreza no Brasil $\quad 17$

2.3. Gastos Familiares 20

2.4. Os Negros e a Pobreza $\quad 21$

2.5. Marketing e Comportamento do Consumidor 26

2.5.1. Atitudes e Comportamento do Consumidor 28

2.5.2. A Teoria Funcional das Atitudes $\quad 29$

2.5.3. Modelo ABC das Atitudes 30

2.5.4. Atitude Pós-Compra 32

3. Método 33

3.1. Pesquisa Qualitativa 33

3.2. Análise dos Dados

3.2.1. Impressões do Entrevistador 36

3.3. Análise dos Dados 37

3.4. Limitações do Método 38

4. O Instituto Beleza Natural $\quad 40$

4.1. Histórico do Instituto Beleza Natural 40

4.2. Definição do Negócio 42

4.2.1. Missão $\quad 42$

4.2.2. Visão 43

4.2.3. Valores 43

4.3. Posicionamento 43

4.4. Consumidor 44

4.5. Recursos Humanos $\quad 45$

4.6. Processo 46

4.6.1. Processo de Atendimento 46

4.7. Produtos e Serviços $\quad 47$

4.7.1. Super Relaxante $\quad 47$

4.7.2. Outros Serviços $\quad 48$

4.7.3. Linha de Produtos $\quad 48$

4.8. Preço 48

4.9. Forma de Pagamento 52

4.10. Ponto 52

4.10.1. Localização das Filiais 53

4.11. Promoção 53

4.11.1. Promoção de Vendas 54

4.11.2. Internet 54

4.11.3. "Turma da Ziquinha"

4.11.4. Central de Atendimento 
5. Resultados

5.1. Problemática 1: As Dificuldas das Mulheres com Cabelos Crespos: O Cabelo Ruim e o Cabelo Bom

5.2. Problemática 2: Experiências das Meninas Negras com o Cabelo

5.2.1. Temática 2.1: O Uso de Tranças

63

5.2.2. Temática 2.2: Preconceito na Escola 64

5.2.3. Temática 2.3: Alvo de Racismo 66

5.3. Problemática 3: O Tratamento do Cabelo Ajuda a Conseguir Emprego

5.4. Problemática 4: O Tratamento do Cabelo Ajuda a Conseguir Namorado

5.5. Problemática 5: Os Sacrifíficios Financeiros para Fazer o Tratamento no Beleza Natural

5.5.1. Temática 5.1: Hierarquia e Prioridade de Gastos:

Tratamento de Cabela x Outros Gastos

5.5.2. Temática 5.2: O Tratamento do Cabelo entra no

Planejamento Financeiro

5.5.3. Temática 5.3: Algumas Clientes Fazem Dívida para Pagar o Tratamento

5.6. Problemática 6: As Excluídas do Beleza Natural 78

5.7. Problemática 7: As que Desprezam o Beleza Natural 80

6. Implicações Gerenciais

83

6.1. Conhecimento do Consumidor da "Base da Pirâmide"

6.2. O Empreendedor Deve Criar Algo que Ele Mesmo Queira Usar

6.3. Recursos Humanos

85

6.4. Cultura Organizacional

86

6.5. "Fábrica de Sonhos" e a Recuperação da Autoestima

87

6.6. Um Produto-Serviço "Vencedor" e Adequado ao

Consumidor

6.7. Mix de Produtos e Serviços Diversificados 88

6.8. Processo de Atendimento 89

6.9. Evidências Físicas $\quad 89$

6.10. Preço e Forma de Pagamento 90

6.11. Satisfação e Propaganda "Boca-a-Boca" 91

6.12. Pobreza: Um Desafio Também para as Escolas de Negócios

7. Conclusão 94

8. Referências Bibliográficas 97

9. Anexo 101

9.1.Roteiro Geral das Entrevistas 101

9.1.1. Roteiro das Entrevistas para Clientes do Beleza Natural 101

9.1.2. Roteiro das Entrevistas para as Não Clientes do Beleza Natural 


\section{Lista de figuras}

Figura 1: A pirâmide econômica mundial 15

Figura 2: Hierarquia dos três componentes da atitude 31

Figura 3: Tabela de preços dos serviços do Instituto Beleza
Natural praticados pela empresa em agosto de 2009.

Figura 4: Tabela de preços dos produtos do Instituto Beleza
Natural praticados pela empresa em agosto de 2009

Figura 5: Esquema das problemáticas com as respectivas temáticas relacionadas

51

Figura 6: Esquema das problemáticas com as respectivas temáticas relacionadas, aplicadas ao Instituto Beleza Natural 57

Figura 7: Esquema da problemática número 1 do Instituto Beleza Natural, com as respectivas temáticas relacionadas 58

Figura 8: Esquema da problemática número 2 do Instituto

Beleza Natural, com as respectivas temáticas relacionadas

Figura 9: Esquema da problemática número 3 do Instituto

Beleza Natural, com as respectivas temáticas relacionadas

67

Figura 10: Esquema da problemática número 4 do Instituo

70

Figura 11: Esquema da problemática número 5 do Instituo

72

Figura 12: Esquema da problemática número 6 do Instituo

78

Beleza Natural, com as respectivas temáticas relacionadas

80

Figura 13: Esquema da problemática número 7 do Instituto

Beleza Natural, com as respectivas temáticas relacionadas 


\section{Lista de tabelas}

Tabela 1: Linhas de pobreza e indigência no Brasil no ano de 2008

Tabela 2: População total e respectiva distribuição percentual, por cor ou raça, segundo as grandes regiões, unidades da federação e regiões metropolitanas - 2007

21

Tabela 3: Distribuição do rendimento mensal familiar per capita das pessoas de 10 anos ou mais de idade, com rendimento de trabalho, entre os $10 \%$ mais pobres e o $1 \%$ mais rico, em relação ao total de pessoas, por cor ou raça, segundo as grandes regiões - 2007

Tabela 4: Média de anos de estudo e rendimento médio mensal de todos os trabalhos, das pessoas de 10 anos ou mais de idade, ocupadas na semana de referência, com rendimento de trabalho, por cor ou raça, segundo as grandes regiões, unidades da federação e regiões metropolitanas 2007

Tabela 5: Salário médio na ocupação principal (10 anos ou mais de idade no Brasil e no Rio de Janeiro)

Tabela 6: Entrevistas realizadas para a presente pesquisa 


\section{Lista de gráficos}

Gráfico 1: Coparação da renda domicilias per capita entre brancos e negros

Gráfico 2: Relação entre porcentagem de negros e renda per capita no município do Rio de Janeiro

Gráfico 3: Relação entre porcentagem de negros e renda per capita no município do Rio de Janeiro sem aglomerado subnormal 